CORRESPONDENCE

\section{Estimation of optic disc size}

EDITOR,-In a recent paper, ${ }^{1}$ Ruben described a technique for estimating the real vertical optic disc diameter using the slit beam height of a Haag-Streit slit-lamp with a $+90 \mathrm{D}$ condensing lens. It is concluded that a slit beam height of greater than $1.4 \mathrm{~mm}$ indicates a vertical disc diameter of greater than $1.88 \mathrm{~mm}$.

Linear magnification is the ratio of image height $\left(h^{\prime}\right)$ (for example, slit beam height) and object height $(h)$ (for example, real vertical disc diameter). Where the total linear magnification of the system is $\mathrm{m}$ (comprising the optical elements of the patient's eye and the condensing lens), the image height in emmetropia may be calculated according to:

$$
\begin{aligned}
& \mathrm{h}^{\prime}=\mathrm{h} . \mathrm{m} \\
& \text { where } \mathrm{m}=-\left[\frac{\mathrm{Fo}}{\mathrm{P}}\right]
\end{aligned}
$$

Fo is the equivalent power of the eye and $P$ the power of the condensing lens. The minus sign indicates an inverted image. The equivalent power of the eye in emmetropia varies between $+53 \mathrm{D}$ and $+64 \mathrm{D}^{23}$ and is normally distributed. The total linear magnification in emmetropia therefore varies between -0.59

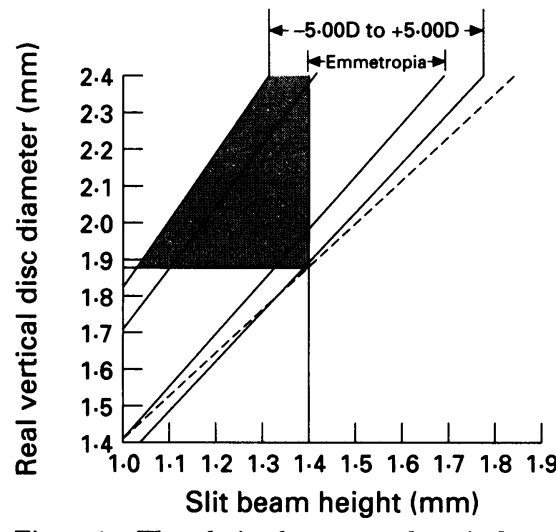

Figure 1 The relation between real vertical optic disc diameter and image height $(+90 \mathrm{D}$ lens) in emmetropia and ametropia $(-5.00 \mathrm{D}$ to $+5 \cdot 00 \mathrm{D}) ;---, Y=1 \cdot 17 . X+0 \cdot 24$. and -0.71 with the $+90 \mathrm{D}$ lens.

The relation between real vertical disc diameter and slit beam height in emmetropia is shown in Figure 1. Ruben's regression line $(\mathrm{Y}=1 \cdot 17 . \mathrm{X}+0 \cdot 24)$ is superimposed.

In ametropia, linear magnification must also take into account the ocular refraction $(\mathrm{K})$, the position of the first principal plane of the eye (e) and the working distance of the condensing lens (q). The image height may be calculated according to:

$$
\begin{aligned}
& \mathrm{h}^{\prime}=\mathrm{h} . \mathrm{m} \\
& \text { where } \mathrm{m}=-\left[\frac{\mathrm{Fo}+\mathrm{K}}{\mathrm{P}-\mathrm{K} \cdot(1-\mathrm{P} . \mathrm{e}+\mathrm{P} . \mathrm{q})}\right]
\end{aligned}
$$

By considering the normal distributions of the ocular elements, the total linear magnification in ametropia $(-5.00 \mathrm{D}$ to $+5.00 \mathrm{D})$ varies between -0.55 and -0.74 (Fig 1 ).

The following observations can be made with regard to Ruben's method:

(1) The regression line, $Y=1 \cdot 17 . X+0 \cdot 24$, is lower than one would expect from theoretical considerations. This may be due to error in image height estimation (SD $0.25 \mathrm{~mm}$ ) and error due to Littmann's method.

(2) The vertical disc diameter of most optic discs is underestimated, the effect being more pronounced with larger discs (Fig 2) and less pronounced overall in hypermetropia (Fig 2C).

(3) In agreement with Ruben, should the slit beam height be greater then $1.4 \mathrm{~mm}$, the vertical disc diameter is almost certain to be greater than $1.88 \mathrm{~mm}$.

(4) The vertical disc diameter, when measured at the dissecting microscope, varies between $1.4 \mathrm{~mm}$ and $2.4 \mathrm{~mm}$ (mean 1.88 $\mathrm{mm}$ ), is normally distributed ${ }^{4}$ and not correlated with low ametropia. ${ }^{5}$ Fifty per cent of vertical optic disc diameters will therefore be greater than $1.88 \mathrm{~mm}$. The shaded area in Figure 1 represents those optic discs estimated at less than, but actually greater than, $1.88 \mathrm{~mm}$, comprising approximately half of such optic discs. Therefore, when the image height is between $1.2 \mathrm{~mm}$ and $1.4 \mathrm{~mm}$, a significant number of optic discs will be greater than $1.88 \mathrm{~mm}$ in diameter.

The optimal quantitative optic disc predictor in glaucoma is the neuroretinal rim area. ${ }^{6}$ Ruben's method cannot be adapted to perform this measurement: magnification due to the optical components of the patient's eye is not considered, it is not possible to estimate the real dimension of cups whose image with

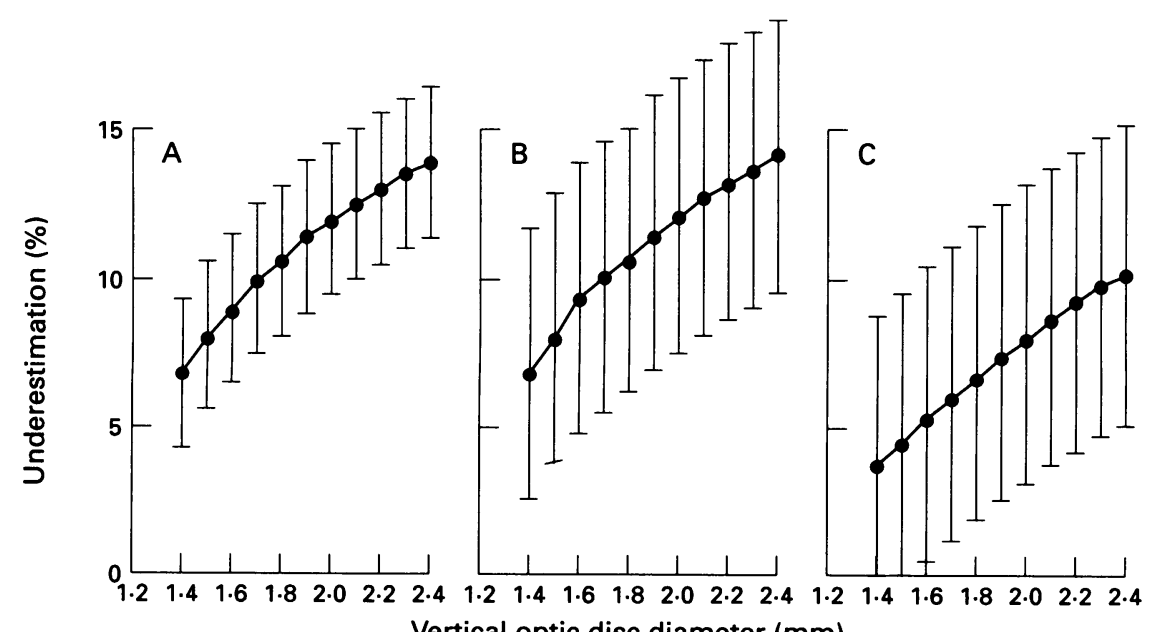

Vertical optic disc diameter $(\mathrm{mm})$

Figure 2 Percentage underestimation (mean (SD)) of real vertical optic disc diameter in emmetropia $(A)$, myopia $(-0.50 \mathrm{D}$ to $-5.00 \mathrm{D})(\mathrm{B})$, and hypermetropia $(+0.50 \mathrm{D}$ to $+5.00 \mathrm{D})$ (C). the $+90 \mathrm{D}$ lens is less than $1.0 \mathrm{~mm}$ and retinal object dimensions are significantly underestimated.

However, there is little doubt that with the $+90 \mathrm{D}$ lens an image height of greater than $1.4 \mathrm{~mm}$ will correctly identify a vertical disc diameter of greater than $1.88 \mathrm{~mm}$ in the majority of cases.

Tennent Institute of hithalmology, Church Street Glasgow G11 6NT

1 Ruben S. Estimation of optic disc size using indirect biomicroscopy. $\mathrm{Br} \mathcal{F}$ Ophthalmol 1994; 78: $363-4$.

2 Tron EJ. Variationsstatische Untersuchungen über Refraktion. Graefes Arch Ophthalmol 1929; 122: 1-33.

3 van Alphen GWHM. On emmetropia and ametropia. Ophthalmologica 1961; 142 (suppl): 1-92.

4 Quigley HA, Brown AE, Morrison JD, Drance SM. The size and shape of the optic disc in normal human eyes. Arch Ophthalmol 1990, 108: 51-7.

5 Britton RJ, Drance SM, Schulzer M, Douglas GR, Mawson DK. The area of the neuroretinal rim of the optic nerve in normal eyes. $A m$ Ophthalmol 1987; 103: 497-504.

6 Airaksinen PJ, Drance SM, Schulzer M. Neuroretinal rim area in early glaucoma. $A m \mathcal{F}$ Ophthalmol 1985; 99: 1-4.

\section{Reply}

EDITOR,-Dr Barr correctly brings to our attention the formulas for linear magnification. However, while the arguments put forward concerning these formulas and their relevance to the technique described are theoretically correct, they would appear to be of little relevance to the use of the technique as described in a clinical setting for the following reasons.

(1) Although the equivalent power of the eye in emmetropia may indeed vary between $+53 \mathrm{D}$ and $+64 \mathrm{D}$, these values represent the extremes. The standard deviation of the distribution has not been stated. The majority of the population may in fact lie within a much narrower range. The range of magnification will likewise be narrower for the majority of the population.

(2) Although the second formula is correct

$$
\mathrm{h}^{\prime}=\mathrm{h} . \mathrm{m}
$$

where $m=-[F o+K / P-K .(1-P . e+P . q)]$

because a high power condensing lens is being used $(90 \mathrm{D})$ and the variation in $e$ and $q$ is measured in metres the difference is in fact quite small. Furthermore, the variation in magnification will depend on whether the emmetropia is axial or refractive in nature (see below). It is clearly stated in the original paper that refractive error will influence image size which is why the method is confined to low emmetropia and why the technique cannot be used as an accurate measure of dimensions. However, should the refraction, keratometry, and axial length of the eye be known then a more exact measurement could be made.

(3) With regard to the first observation the regression line is different because it is based on clinical methods and not purely on theoretical grounds. It must be stated that all optic discs studied in this paper were clinically within normal limits and the conversion factor obtained relates to the image size estimated using a planimetric device and not that found at autopsy.

(4) With regard to the second observation: because this technique is designed as an aid to clinical assessment and not as a method for exact measurement, underestimation of size 
will increase the sensitivity of the technique which is what is required of a screening method. Once again underestimation is only in relation to autopsy findings and not to the actual clinical findings where the points are evenly distributed each side of the regression line.

(5) With regard to the third observation: this observation agrees with what is the only real punchline of the whole paper and the proposed use of the technique described.

(6) With regard to the fourth observation: this is a different interpretation of the second observation. The same conclusion as in (4) above therefore applies.

The criticism regarding application of the technique to measurement of neuroretinal rim area is unjustified and unsupported. Furthermore such a use of the technique has not been postulated. It is merely pointed out that large discs have larger neuroretinal rim areas regardless of cup/disc ratio as long as there are no abnormal features on clinical examination.

Nowhere is it proposed that this technique can be used for measuring optic disc dimensions accurately. On the contrary, it is clearly stated to be a quick and easy clinical method of estimating (defined by the Oxford English Dictionary as 'an approximate judgment') disc size which may be of help in patients with large physiological cups or asymmetric cups.

This letter has correctly stated the formulas for linear magnification that can be found in any textbook of physiological optics. It has not come to any conclusions about that effect nor does it contradict the purpose for which the technique was described and is in fact in agreement with the conclusions in the paper.

To further illustrate how little the variables mentioned will actually alter the use of this technique the following examples have been calculated (Colin Fowler, Department of Vision Sciences, Aston University, Birmingham, personal communication).

\section{LENS MAGNIFICATION}

Assume the Volk $90 \mathrm{D}$ lens to be a 'thin' lens, place at $20 \mathrm{~mm}$ from the eye.

Using the simplified schematic eye, standard power $+60 \mathrm{D}$ for emmetropia, refractive index $1 \cdot 333$, axial length $22 \cdot 22 \mathrm{~mm}$. For axial ametropia, change the length of the eye, for refractive ametropes change power.

\section{(1) Axial hypermetropia}

Assuming an axial length of $20 \mathrm{~mm}$, equivalent to +6.5 D hypermetropia. Magnification produced by $90 \mathrm{D}$ lens: $0.7 \times$.

\section{(2) Axial myopia}

Assuming an axial length of $24 \mathrm{~mm}$, equivalent to $-4.46 \mathrm{D}$ myopia. Magnification produced by $90 \mathrm{D}$ lens: $0 \cdot 64 \times$.

\section{(3) Refractive myopia}

Assuming power of eye is $+65 \mathrm{D}$, giving $-5 \mathrm{D}$ myopia. Magnification with $90 \mathrm{D}$ lens: $0 \cdot 7 \times$.

\section{(4) Refractive hypermetropia}

Assuming power of eye is $+55 \mathrm{D}$, giving $+5 \mathrm{D}$ hypermetropia. Magnification with $90 \mathrm{D}$ lens: $0.63 \times$.

\section{(5) Emmetrope}

Magnification produced by volk lens $0.67 \times$ if power of eye remains at $60 \mathrm{D}$.

\section{CHANGE IN POSITION OF LENS}

In the case of an emmetrope magnification will be constant.

In ametropia, consider the following example of a $24 \mathrm{~mm}$ axial myope, as in (2) earlier:

Position of $90 \mathrm{D}$ lens

$\begin{array}{llll}\text { Position of } 90 \text { D lens } & & & \\ \text { from eye: } & 20 & 30 & 40(\mathrm{~mm}) \\ \text { Magnification: } & 0.64 & 0.67 & 0.71\end{array}$

It can be seen from these examples that the range of magnification in emmetropia is much less than suggested in Barr's letter. Also that to alter significantly the image size the lens would have to be moved a considerable distance and this does not occur in clinical practice.

SIMON RUBEN 1 Halford Road, West Midlands B91 1DL

\section{Laser flare intensity in diabetics}

EDITOR,-We congratulate Ino-ue and colleagues on their article recently published in the BfO. ${ }^{1}$ Many of their findings agree with our previously published article on this subject. ${ }^{2}$ The controlled groups in our study ${ }^{2}$ had similar flare values to those reported ${ }^{1}$ and we conclude similarly that patients with more severe proliferative or regressed proliferative retinopathy have greater flare values than those without retinopathy. However, our results differ since in our study diabetics, even without diabetic retinopathy, had significantly greater flare values than normal controls, as did all patients with background diabetic retinopathy. Ino-ue et al find no difference between diabetics without retinopathy and normal subjects at any stage and a significant difference between background retinopathy and normals only after five decades.

Our findings of increased breakdown of the blood-aqueous barrier in diabetes without coexistent retinopathy, or preceding its development, is borne out by two other studies. Fluorescein angiographic changes in iris vasculature occur before breakdown of the blood-retinal barrier. ${ }^{3}$ In addition, the well known association of uveitis with diabetes consistently precedes the development of retinopathy. 4

No statement on control of diabetes is made in the patient data analyses reported. ${ }^{1}$ Hypoglycaemic therapy may have had a significant effect on these results, since initiation of treatment is known to affect and delay the development of retinopathy and reduce blood-retinal barrier dysfunction in animals. ${ }^{5}$ It is unknown whether this can be extrapolated to humans. Use of insulin in $25 \%$ of our patients with no retinopathy ${ }^{2}$ may have normalised blood-retinal barrier dysfunction and hence prevented or delayed the appearance of diabetic retinopathy, but did not affect blood-aqueous barrier dysfunction to the same extent. This may account for a higher flare value in diabetics, even without retinopathy, compared with normals. This merits consideration when all diabetics undergo anterior segment surgical procedures or laser photocoagulation. ${ }^{6}$

A P MORIARTY Department of Ophthalmology, Department of Ophthalmology,
Royal Liverpool University Hospital,
Liverpool D J SPAITON St Thomas's Hospital,

1 Ino-ue M, Azumi A, Shirabe H, Tsukahara Y, Yamamoto $M$. Laser flare intensity in diabetics: correlation with retinopathy and aqueous protein concentration. $\mathrm{Br} \mathcal{F}$ Ophthalmol 1994 78: 694-7.
2 Moriarty AP, Spalton DJ, Shilling JS, ffytche TJ Studies of the blood-aqueous barrier in diabetes mellitus. Am f Ophthalmol 1994; 117: 768-71 3 Klein S, Marre E, Zenker HJ, Koza KD. Zur Korrelation von diabetischer Irido-und Retinopathie. Fortschr Ophthalmol 1983; 79: 428.

4 Rothova A, Meenken C, Michels RP, Kijlstra A. Uveitis and diabetes mellitus. Am $\mathcal{f}$ Ophthalmol 1988; 106: 17.

5 Kernell A, Arnqvist $H$. Effect of insulin treatment on the blood-retinal barrier in rats with streptozocin-induced diabetes. Arch Ophthalmol 1983; 101: 968 .

6 Moriarty AP, Spalton DJ, Shilling JS, ffytche TJ Breakdown of the blood-aqueous barrier following pan-retinal photocoagulation for prolif erative diabetic retinopathy. Am $\mathcal{f}$ Ophthalmol 1995 (in press).

\section{Reply}

EDITOR,-The laser flare intensity is a quantitative indicator in the evaluation of diabetic dysfunction of the blood-ocular barrier without tracers. The laser flare intensity correlated with the degree of retinopathy. ${ }^{1-3}$ However, a recent report ${ }^{4}$ has indicated a significantly higher flare intensity in eyes without retinopathy. Fluorescein iris angiography ${ }^{5}$ and fluorophotometry $^{6}$ have demonstrated that the blood-aqueous barrier dysfunction precedes breakdown of the blood-retinal barrier. Moriarty et al $^{4}$ have discussed a greater tendency of insulin to produce blood-aqueous barrier dysfunction. In our study most of patients without retinopathy was non-insulin dependent. The effect of insulin on the bloodaqueous barrier and the laser flare intensity should be evaluated. Whereas, a tracer of fluorescein has a small molecular size, the laser flare intensity reflects the larger molecular size of proteins. Leakage of various materials depends on the degree of the dysfunction of barrier. Even if fluorescein leakage has been observed, the laser flare intensity may not be elevated. In young diabetic patients without retinopathy, fluorescein iris angiography revealed a higher incidence of dye leakage than normal controls, but no difference in the laser intensity was observed. ${ }^{7}$ Shah et al ${ }^{8}$ has suggested that fluorophotometry and laser flare cell metry may measure different variables of the blood-aqueous barrier. Blood-aqueous barrier function at the early stage of diabetes should be simultaneously evaluated with iris angiography, fluorophotometry, and laser flare cell metry.

$$
\begin{array}{r}
\text { MASANORI INO-UE } \\
\text { Department of Ophthalmology, } \\
\text { School of Medicine, } \\
\text { Kobe University, } \\
\text { 7-5-2 Kusunoki-cho, Chuo-ku, } \\
\text { Kobe 650, fapan }
\end{array}
$$

1 Azumi $A$, Shirabe $H$, Ino-ue $M$, Yamamoto $M$. Aqueous flare in diabetes and normal subjects. 2 Oshika T, Kato S, Funatsu H. Quantitative assessment of aqueous flare intensity in diabetes. Graefes Arch Clin Exp Ophthalmol 1989; 227: 518-20.

3 Ino-ue $M$, Azumi $A$, Shirabe $H$, Tsukahara $Y$, Yamamoto $M$. Laser flare intensity in diabetics: correlation with retinopathy and aqueous protein concentration. $\mathrm{Br} \mathcal{F}$ Ophthalmol 1994 78: 694-7.

4 Moriarty AP, Spalton DJ, Shilling JS, ffytche TJ. Studies of the blood-aqueous barrier in diabetes mellitus. Am f Ophthalmol 1994; 117: 768-71.

5 Klein S, Marre E, Zenken HJ, Koza KD. Zur Korrelation von diabetischer Irido-und Retinopathy. Fortscher Ophthalmol 1983; 79: 428-30.

6 Yoshida A, Ishiko S, Kojima M, Ogasawara M. Permeability of the blood-ocular barrier in Permeability of the blood-ocular barrier in adolescent and adult diabetic

7 Shirabe H, Azumi A, Ino-ue M, Yamamoto $M$ Iris angiographic finding and aqueous flare in early stage diabetic eyes. Folia Ophthalmol fpn 1992; 43: 1499-501. 